* DOE/NN- -98006397

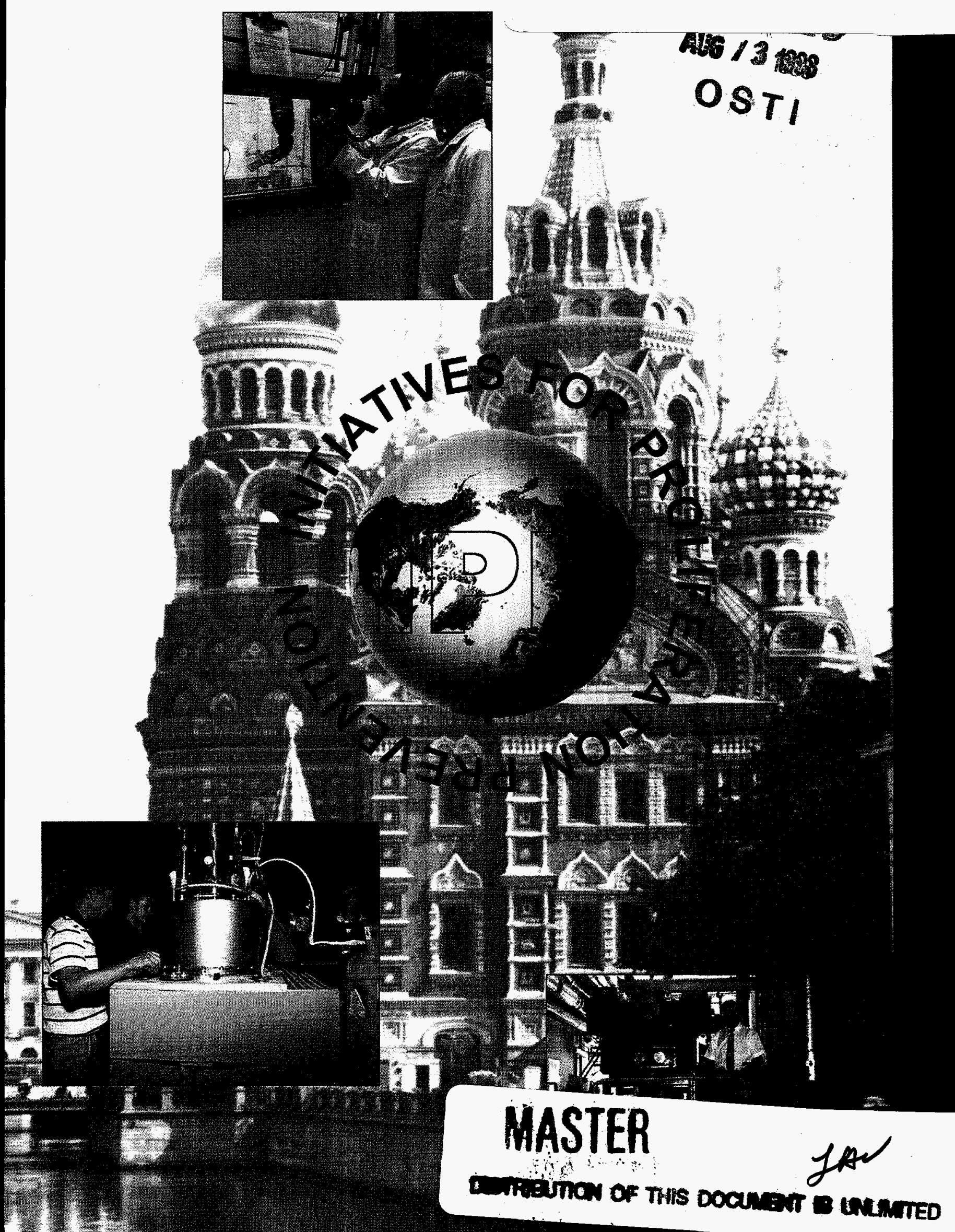




\section{DISCLAIMER}

This report was prepared as an account of work sponsored by an agency of the United States Government. Neither the United States Government nor any agency thereof, nor any of their employees, makes any warranty, express or implied, or assumes any legal liability or responsibility for the accuracy, completeness, or usefulness of any information, apparatus, product, or process disclosed, or represents that its use would not infringe privately owned rights. Reference herein to any specific commercial product, process, or service by trade name, trademark, manufacturer, or otherwise does not necessarily constitute or imply its endorsement, recommendation, or favoring by the United States Government or any agency thereof. The views and opinions of authors expressed herein do not necessarily state or reflect those of the United States Government or any agency thereof. 


\section{DISCLAIMER}

Portions of this document may be illegible in electronic image products. Images are produced from the best available original document. 


\section{Introduction}

Preventing the proliferation of weapons of mass destruction is a central part of United States (U.S.) national security policy. A principal instrument of the Department of Energy's (DOE's) program for securing weapons of mass destruction technology and expertise and removing incentives for scientists, engineers and technicians in the newly independent states (NIS) of the former Soviet Union to go to rogue countries or assist terrorist groups is the Initiatives for Proliferation Prevention (IPP). IPP was initiated pursuant to the 1994 Foreign Operations Appropriations Act. IPP is a nonproliferation program with a commercialization strategy.

IPP seeks to enhance U.S. national security and to achieve nonproliferation objectives by engaging scientists, engineers and technicians from former NIS weapons institutes; redirecting their activities in cooperatively-developed, commercially viable non-weapons related projects. These projects lead to commercial and economic benefits for both the NIS and the U.S. IPP projects are funded in Russia, Ukraine, Kazakhstan and Belarus.

The principal goal of IPP is to stabilize personnel and resources in the NIS that represent a potential proliferation risk. Dramatic budget decreases at NIS institutes where these individuals work and live, and the opportunity for meaningful alternate employment is a significant proliferation concern. IPP seeks to address the incentives facing weapons scientists, engineers, and

technicians operating in and around facilities with technology, materials, and equipment of concern.

The first IPP contracts were signed in August, 1994. "Umbrella" contracts already in place with the Russian Nuclear Centers were used to move quickly to engage our nuclear weapons counterparts in the NIS. A subcontract was signed with the Russian Federal Nuclear Center at Sarov (Arzamas-16) to develop a practical method of neutron passportization for source configuration control. This was the first IPP project to be completed, and the technology is already integrated into jointly developed materials protection, control, and accounting systems in Russia. This work was also an indication of how IPP can directly contribute to other nonproliferation efforts. IPP continues to emphasize coordination and integration with programs having similar objectives.

The approach of IPP is three-fold. First, the DOE national laboratories work with the NIS institutes to identify and evaluate the commercial potential of research and development at NIS institutes. Second, approved partnerships are cost-shared by U.S. industry. Finally, commercialization is achieved allowing U.S. Government funding to taper off leaving a profitable relationship between the NIS institute and the U.S. industrial partner. The program leverages NIS intellectual capital, provides seed money to speed activity and lessen delay caused by uncertainty, and generates private sector-funded, self-sustaining projects that promote alternative peaceful employment and long-term stability for these individuals of concern.

To date, over 360 projects have been funded - 85 percent with institutes in the Russian Federation - including over 300 "Lab-to-Lab" projects (Thrust I) and 
over 60 industry cost-shared projects (Thrust II). Of the latter projects, DOE's investments have been matched at a proportion of almost $\$ 2$ of private sector contribution for each $\$ 1$ of DOE contribution. Projects have engaged over 4,000 weapons scientists, engineers and technicians on projects in areas as diverse as materials science, biotechnology, instrumentation, medical isotopes, and nuclear safety. A capability exists to track these projects from inception, monitoring progress using project metrics and tracking incorporated in a computer-based information system.

IPP participants have been encouraged by the results of these projects. The performance of the NIS colleagues on many projects has exceeded original expectations. There are numerous opportunities to benefit other DOE programs with the modest investments required to engage the NIS institutes. More significant is the quality and nature of the technical work, which is often innovative and different from the U.S.

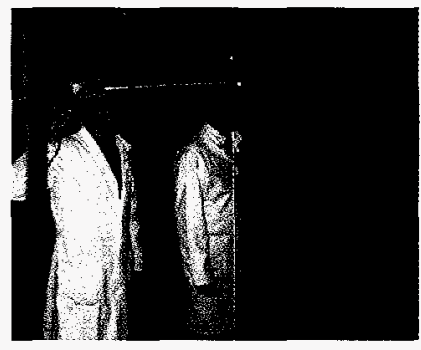
approach to similar issues. The most successful collaborations are those which complement ongoing DOE programmatic activities.

Ten DOE multiprogram laboratories participate in the program: Argonne National Laboratory, Brookhaven National Laboratory, Idaho National Engineering and Environmental Laboratory, Lawrence Berkeley National Laboratory, Lawrence Livermore National Laboratory, Los Alamos National Laboratory, National Renewable Energy Laboratory, Oak Ridge National Laboratory, Pacific Northwest National Laboratory, and Sandia National Laboratory. The DOE Kansas City Plant participates also, serving as a full scale manufacturing demonstration site that can transition laboratory research and development concepts into manufacturing products in order to reduce potential risks and bring new products to the market in the shortest possible time.

In 1994, the U.S. Industry Coalition (USIC) was established to facilitate commercial interactions between U.S. businesses and entities in the NIS. The operational headquarters for USIC are located at the University of New Mexico, which also provides support for membership services and proposal management. USIC seeks to promote commercial opportunities both within the U.S. and NIS by encouraging U.S. industry trade and investments in the NIS. USIC's role in bringing suitable industry partners into all stages of IPP project development ensures that the program focuses only on technology and research with strong potential that industry is willing to invest in. Currently, sixty U.S. companies and universities are members of USIC.

The Nuclear Cities Initiative is an important new focus of the IPP program growing out of the Gore-Chernomyrdin Commission meeting in March, 1998. IPP, other DOE, and U.S. Government programs will formally engage with the Russian Ministry of Atomic Energy (Minatom) in helping to assist in the transition of the ten closed, nuclear cities of Russia into the civilian economy. These are cities that are part of the former Soviet nuclear weapons complex. They are both large and isolated, which makes economic transition difficult. Focus will be on IPP projects that can create enterprises in the closed cities to employ former weapons scientists and engineers. IPP will direct its resources to the closed cities as part of this program. IPP has already engaged the closed, nuclear cities with discrete projects at Sarov (Arzamas-16), Snezhinsk (Chelyabinsk-70), Ozersk (Chelyabinsk-65), Seversk (Mayak) and Zheleznogorsk (Krasnoyarsk-26). Initial activity will focus on planning projects and needed resources jointly with Minatom, while encouraging 
interagency participation of both the U.S. and Russian Governments.

IPP is an active member of the U.S. Government nonproliferation community and seeks to synergize and leverage the efforts of other programs with common and comparable goals. Thus, IPP is an investment in U.S. national security, not foreign aid. While the IPP program cannot alone solve the NIS expertise and technology proliferation problem, the program's diverse participants can contribute to a solution. IPP is organizationally located in the DOE Office of Nonproliferation and National Security.

This booklet offers an overview of the IPP program as well as a sampling of some of the projects which are currently underway. For more information, please contact any of the individuals listed at the inside back cover. 


\section{Creating a Commercial Silicon Enterprise}

The goal of this IPP project is to convert a portion of the Russian plutonium infrastructure at Krasnoyarsk-26 (K-26) into a commercial endeavor. A \$170 million dollar polycrystalline silicon plant will be built with private financing to produce 1,000 metric tons per year of this material at K-26 and create approximately 800 Russian jobs. Polycrystalline silicon is the basic feedstock used to produce integrated circuits. The success of this project has many strategic implications for the US Government and domestic semiconductor industry. The Japanese control $75 \%$ of the world market for this material. The remaining $25 \%$ of the market is controlled by the Germans. Russia could be a third source and the resulting market diversity could moderate the pricing and provide a more reliable supply base for our domestic semiconductor industry. Without Russian participation, there will be a substantial world wide production shortfall and strong pricing of this material for the next 5 years. Also, it is anticipated that a significant fraction of this capacity will be used to supply Russian domestic demand as, for example, some of the high purity trichlorosilane gas will be used in Novosibirsk to produce solar cells.

\section{Building a Team}

A workshop was held at Sandia in December, 1996 to solicit the opinions of US and Russian financial, technical, business, and government experts to determine the most efficient, lowest risk, approach to move this project forward and create a world class production facility. As a result of this workshop, the Defense Enterprise Fund (DEF) agreed to manage the project in return for a $4 \%$ equity stake in the business. A joint venture has been formed, a very favorable long term electrical power contract has been signed, and negotiations are currently underway with the Russian Federation to obtain tax concessions. In addition, the Russian Federation will contribute approximately $\$ 17$ million dollars toward this project. DEF has contracted with Rose Associates to provide the market analysis. The European Bank For Reconstruction has shown preliminary interest in participating in this project. Discussions have also been underway with Western companies that produce silicon to join the project as a strategic investors. To date the DEF has invested approximately $\$ 400,000$ of risk capital into this project.

\section{Business Plan}

Sandia, working with IPP Program funds, agreed to manage contracts for a technical feasibility study of the Russian technology $(\$ 100,000$ to Polycrystalline Silicon Technologies) and a business plan ( $\$ 100,000$ to Ernst \& Young, Moscow). At the present time a search is underway to enlist a US strategic investor and to locate capital in the international financial community. 


\section{Successful Partnership Achieves Progress in Removing Radiation from Milk Products}

Cesium- 137 is estimated to account for about $80 \%$ of the radiation dose to humans in Ukraine following the Chernobyl accident. This IPP project has allowed Argonne National Laboratory and Ukrainian scientists to test and develop Selentec's MagSep SM technology to selectively remove cesium-137 from milk. This technology uses specially formulated particles to absorb and sequester the cesium. The particles are mixed with the milk to allow for cesium absorption and are then retrieved from the milk by magnetic filtration. This technology has received an R\&D 100 Award.

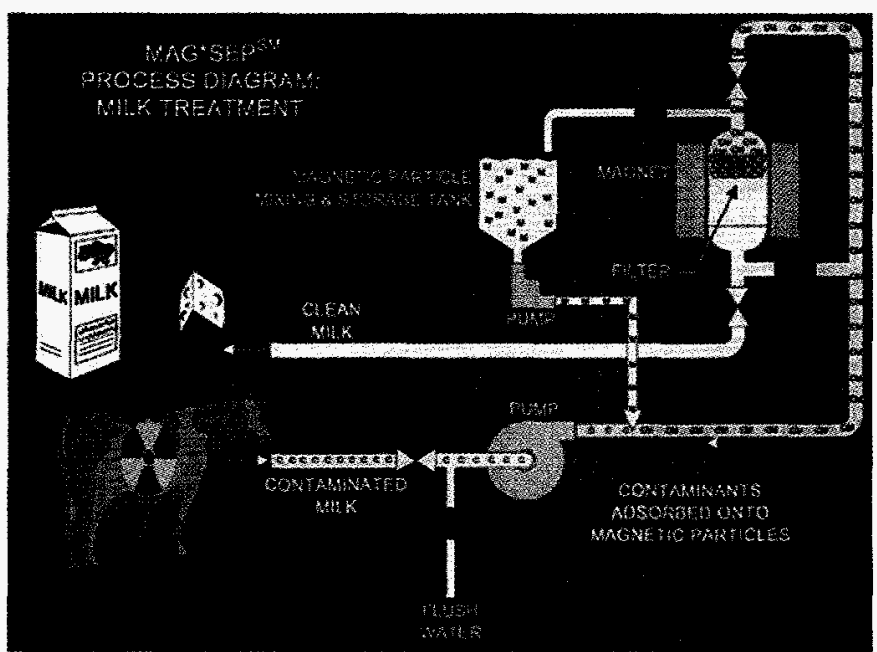

Funding from the IPP program, matched by inkind contributions by Selentec, has supported a coordinated effort by scientists at Argonne and in Ukraine to select the most suitable particle type and to develop performance data and engineering

parameters for this application of the technology. Such process variables as particle dosing, contact time, and number of uses have been tested by both teams, while Argonne has undertaken development of methods to assess and control microbial growth and fouling. These methods will be completed in the second year of work and are being transferred to the Ukrainian team, who will test them under operating conditions on the first prototype milk-treatment equipment; this equipment has been built and set up by Selentec at the dairy plant in Ovruch, Ukraine.

Argonne's role has included the distribution of funding to Ukraine by managing the subcontract with the State Committee of Ukraine on Food Industry (SCUFI). The SCUFI coordinates the efforts of more than 15 scientists, engineers, and technicians formerly or currently employed by the Scientific Center for Radiation Medicine, the Arsenal Factory, the Paton Electric Welding

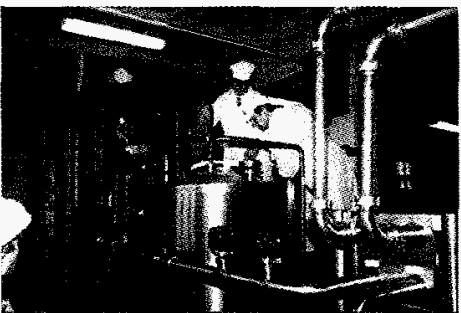
Institute, the Institute for Strength of Materials, and the Institute of Ultrahard Materials in Kiev. In addition to providing several dozen man-years of commercial activities for former weapons scientists, this project is expected to benefit economically both the US partner and the Ukraine by increasing sales related to milk and dairy products.

Close coordination and communication between the teams have helped ensure the timely generation of test data in support of Selentec's efforts in designing and building the prototype equipment. 


\title{
TUNGSTEN CARBIDE (WC-Co) RECYCLING
}

\author{
Faster, Cheaper, Cleaner with RUSTEC Technology
}

One of the most common cemented carbides consists of tungsten carbide particles cemented with cobalt as the binder. Cemented tungsten carbide (WC$\mathrm{Co}$ ) is very hard, strong and wear resistant. It competes with diamond for many industrial as well as military applications. It is used extensively for metal cutting, mining, construction, rock drilling, metal forming, and other structural and/or wear applications. It has been used in armor piecing shells as well as in the fabrication of nuclear weapon systems.

Cemented tungsten carbide is expensive so recycling is desirable. Tungsten carbide recycling technology is very energy intensive - using combinations of mechanical, chemical, and thermal processing to retrieve the tungsten and/or tungsten carbide material for re-use.

The RUSTEC mechanical grinding technology provides an improved technology for advanced mechanical reduction of tungsten carbide components for direct use in either thermal spray applications and/or optimized sizing for reclamation. The RUSTEC process entails no air emissions or chemicals and overall energy use is dramatically reduced. The process employs an innovative vibratory crushing/ grinding technique that was developed at a Russian mining institute in St. Petersburg, Russia.

Under the Cooperative Research and Development Agreement (CRADA) between RUSTEC and Oak Ridge National Laboratory, the technique was improved to recycle solid tungsten carbide components into fine powders. The technique can be readily adapted to provide powders that precisely meet the customer's specifications thereby permitting direct use in many applications.

RUSTEC has supplied powders to such tungsten carbide giants as Kennametal, Teledyne and Osram Sylvania. RUSTEC is manufacturing powders and selling them on the open market. Interest in RUSTEC powders has been generated throughout the US and in the United Kingdom.

The RUSTEC technology also has been successfully used to recycle armor-piercing shells into powder for industrial tooling applications.

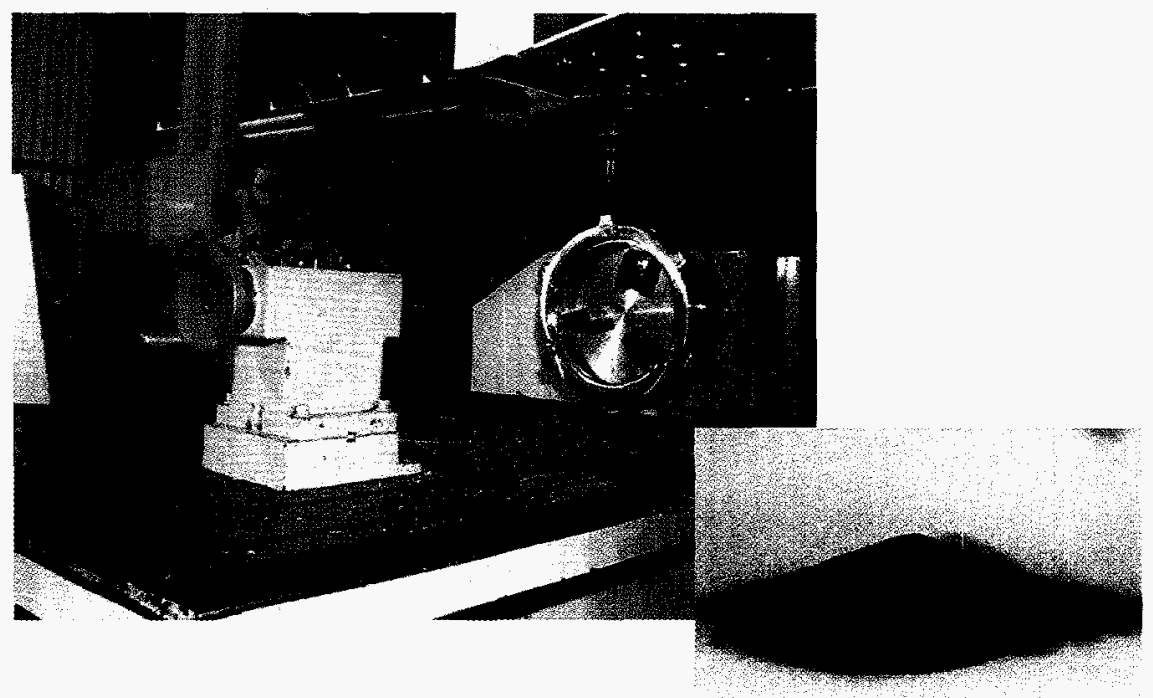




\section{Sovlux- Building a Manufacturing Facility for Amorphous Silicon Photovoltaic Products}

This project capitalizes on an investment made by the former Soviet Union to implement amorphous silicon photovoltaic module manufacturing technology in Moscow through KVANT and other laboratories. A US-Russian joint venture, Sovlux, has been established between KVANT and Energy Conversion Devices (ECD) of Troy, MI. Earlier support through the IPP program helped to make the facility in Moscow operational. This project will focus on developing material and cell techniques to develop multi-junction, multi-bandgap thin-film photovoltaic products with state-of-the-art efficiencies. The improvements from this project will be incorporated into production processes at ECD (US) and at Sovlux's (Russia) 2 Megawatts production line. Developing technology to address the most viable near-term markets for amorphous silicon photovoltaic product should benefit the Sovlux plans to become an economically viable entity. In addition, various other opportunities were identified to develop new technologies to enhance the competitive production of amorphous silicon photovoltaic and other products. These technologies would be transferable to amorphous silicon product manufacturers elsewhere, and address topics that are frequently mentioned but not actively addressed by US amorphous silicon manufacturers.

A major market niche for amorphous silicon has been identified in the production of photovoltaic roofing materials such as shingles and larger roofing modules. Program support will be used to upgrade the "backend" of the module manufacturing line to produce such products. In collaborations between Sovlux, the Institute of Thermophysics in Novosibirsk, the All Russian Institute of Chemical Technology (ARRICT) and ECD and National Renewable Energy Laboratory a deposition process ("plasma gas jet") is being investigated which promises to enhance manufacturing capacities of current amorphous silicon manufacturing lines by allowing to increase deposition rates and thereby plant throughput, while maintaining good electronic quality and stability in the deposited thin-film semiconductor layers. Technology know-how has been identified at ARRICT to recover and repurify the recovered gases from the effluent stream of the amorphous silicon manufacturing line. Technology to capture and repurify the most costly gases from the effluent stream will be developed.

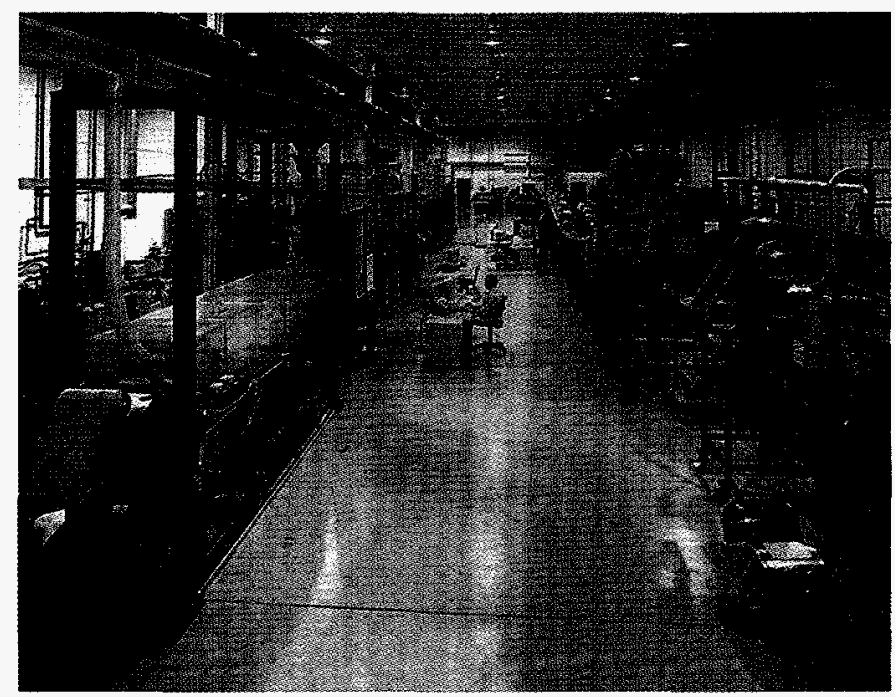




\section{NIS Institutes Involved with IPP}

\section{Belarus} Institute of Radio Ecological Problems (IREP) Physical-Technical Institute - BAS
Institute of Power Engineering Problems

\section{Russian Federation cont.}

A. V. Shubnikov Institute of Crystallography Budker Institute Of Nuclear Physics

Center of Instrument Engineering for

Geophysics and Ecology

Central Institute of Aviation Motors

Chelyabinsk Polytechnic Institute

\section{Kazakstan}

Institute of Geophysical Research

Kazak State University

Laboratory of Ion-Exchange Resin

Institute of Chempal Sciences

National $C$ AXtr on Biotechnogy

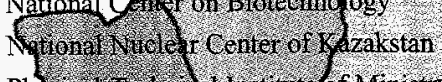

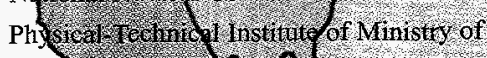

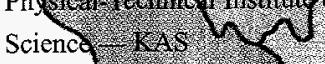

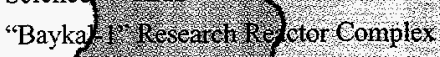

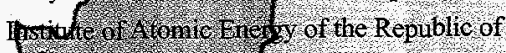

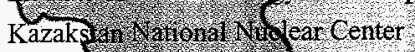

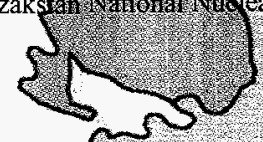

(2)<smiles>[C]1[CH]C1</smiles>

\section{Russiar Federation}

All-Russian Sfientifie Research lns Nuclear Power jant Operation All-Russian Electhal En Éneering Instit. All-Russian Institut of S fientifigand Te Information

All-Russian Light Alloy Institute All-Russian Scientific Research in Theoretical Physics

All-Russian Scientific Research Institute of Automatics

All-Russian Scientific Research Institute of Chemical Technology

All-Russian Scientific Research Institute of Experimental Physics

All-Russian Scientific Research Institute of

\section{Technical Physics}

All-Union Association of Engineers for Heating, Ventilation, Air Conditioning, Heat Supply, and Building Thermal Physics ( $A B O K$ )

Andreyey Acoustics Institute

Association of Centers for Engineering and Automation

A. A. Bochvar All-Russian Scientific Research Institute of Inorganic Materials - Siberia Branch (VNIINM-SB) - Minatom

A. A. Bochvar All-Russian Scientific Research Institute of Inorganic Materials (VNIINM)

A. F. Ioffe Physical - Technical Institute - RAS
Chelyablins StRe University of Technology Chijhprom

6. Effh ov scipntific Institute

Electical Physics Institute (EPI)

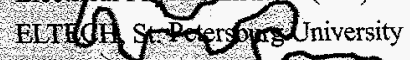
Englehardt Institute of Trolecula? B ENTEK

Experimental Plant for the Besigh and Manufacturing of Scientific Equipment Russian A cadeny of Sciences (EZNP)

Federal Center of Double Technologies "Soyuz GAMALEYA Institute of Epidemiology \& Microbiology

General Physics Institute (GP)

\section{GNPP Nedra}

Gosstroy Mesh Institute, Electromechanica

High Energy Density Research Center

NEOS Institute, Moscow:

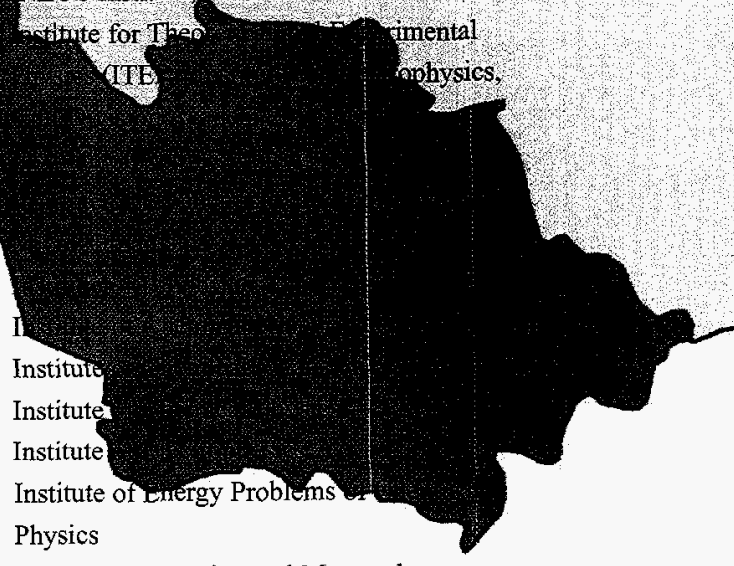

Institute of Experimental Meteorology

Institute of General Physics

Institute of Genetics and Selection of Industrial

Organisms

Institute of Geoelectromagnetic Research

Institute of Geology of Ore Deposits,

Petrography, Minerology, and Geochemistry

Institute of High Current Electronics

Institute of High Energy Physics

Institute of Hygiene, Toxicology and

Occupational Pathology

Institute of Introscopy

Institute of Laser Spectroscopy

Institute of Mechanics Ufa Branch of RAS 
Institute of Metal Physics - RAS

Institute of Metallurgy

Institute of Metals Superplasticity Problems Institute of Nuclear Research - RAS Institute of Nuclear Research INTEAR Ltd. Institute of Petroleum Chemistry Institute of Physical Chemistry-RAS Institute of Physics and Power Engineering Institute of Physics of Advanced Materials Institute of Power Engineerinf Toblems Institute of Problems of 1 trophysics Institute of Protein ReSerfch

4 matitute of Solid State Physics 11is tite of Spectroscopy, Troly 7 stitute of Theretral and Exoctinental Prosses

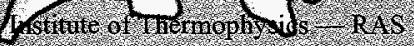
NIIERSOI ARCENTER

1.W. ranizevich histinte for Probterns of Materiat Science

11241. tiolent

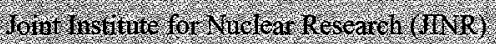
IsC Biod hinninash

Karpor Insintite of Che meal Phy sies. Kranshovatsd ? onice hnical histivite Rrasiaya 7ryezda - (Red Star) Stare Enherpise Rrasnoyarsk whing \& chenreal conbine IVANI, Sovlut L aboratory for IIgh Energy Aandau hrstinte of Theoretieal Physics. Mechancal Engineering Reseate h Instinate. $\mathrm{Mran}$

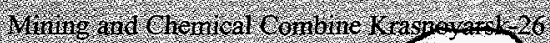
Winstry 0 f t itonic linergy (Winf fom) Noseow Engineening Physies hastithte (MEPhI) Moscon Stale linversiog

Moscon Steel and Iron histivite? ULC ATEX

NPO Astrophysics

Nuclear Safety Institute - RAS

N. D. Zelinsky Institute of Organic Chemistry Production Enterprise Mayak

P. N. Lebedev Physical Institute - RAS

P. P. Shirshov Institute of Oceanology

Republican Engineering Technical Center

Research and Development Institute of Power Engineering

Research Institute of Atomic Reactors

Russian Academy of Electrotechnical Sciences Russian Materials Science Center Tomsk Russian Research Center - Kurchatov Institute Science Center of Applied Problems in Electrodynamics

Semenov Institute of Chemical Physics Shemyakin Institute of Bioorganic Chemistry Siberian Chemical Combine (SKhK) SKB "Geotechnika"

Soliton Scientific and Research Center
State Committee for Uses of Nuclear Energy State Research and Production Corporation State Research Center of Virology and Biotechnology "Vectop?

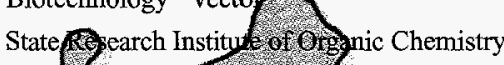
and 12 h St. Petersharg Minny fontitute Thermftrananics center) Tomsk R s seareh lastitur of Inu scopy Topehier Instrute of Petochenical Synthesis (fiss)

Troirs Linsitute for Mimovatien and Fusion

Research ( (inaton) ) ?

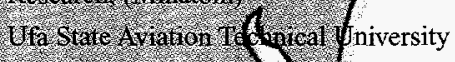

Urals Hining abd Gealog 4 cademy

Urals Polvtedanic nstut

V7lor sute Oplugal Insti hit

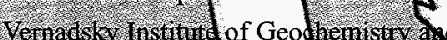
Analvitical chenisg?

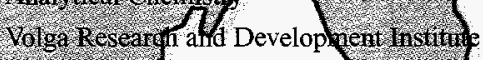
Vorgograd Rirov Khimprom Protiction Assoctition

V. N. 4 akul Institute for Superhard Materi) V.6. (hlopin Radium Institute, (Minatom)

\section{Ukiaine}

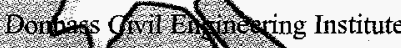
Ginshikof Institute pl bennetics Ninist, of porich or Ukatie histitute for Single Co r tals Institute of Conicersion probldes: Perspective Technologies

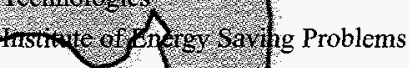

Institute of Gedlogical fcience - UAS

Institute of $\mathrm{Mat}_{\mathrm{H}}$ inds s sience

Institute of Mal Phy sics - UAS

Institute of Mifotology and Virology

Ukrainian Acactemy of Sciences

Institute of Physics and Power Engineering

Institute of Special Mechanical Problems

Institute Of Thermal Physics

Kharkov Technical Physics Institute

Kyyiv Institute Of Materials Science

National Academy of Sciences of Ukraine

Paton Welding Institute

State Committee of Ukraine on Food Industry

State Metallurgical Academic University

Thermodynamics Center

Ukrainian State Committee on Nuclear and

Radiation Safety

V.I. Vernadskii Institute/YUNK-Bureau, LTD. 


\section{Identifying Toxic and Hazardous Substances}

In response to the growing, worldwide need to determine in situ the contents of assorted containers of munitions, chemical weapons, and toxic materials, Lawrence Livermore National Laboratory is developing a new chemical-assay tool in collaboration with Idaho National Engineering and Environmental Laboratory (INEEL), two MINATOM institutes [the All-Russian N.L. Dukhov Research Institute of Automatics (VNIIA, project lead) and the Russian Federal Nuclear Center, All-Russian Research Institute of Experimental Physics (VNIIEF)], and a commercial partner, EG\&G ORTEC. This development is jointly funded by the International Science and Technology Center and the Initiatives for Proliferation Prevention program. More than forty NIS scientists are currently employed by this project.

These applications require field portability, reliability, and ease-ofuse. This nondestructive chemicalassay tool identifies the contents of munitions and chemical-storage containers safely and reliably using special fingerprinting algorithms. The technique uses an electrically driven, ion-tube accelerator that produces pulses of 14-MeV neutrons, as used in Lawrence Livermore's system. The accelerator replaces a lower-energy californium- 252 source

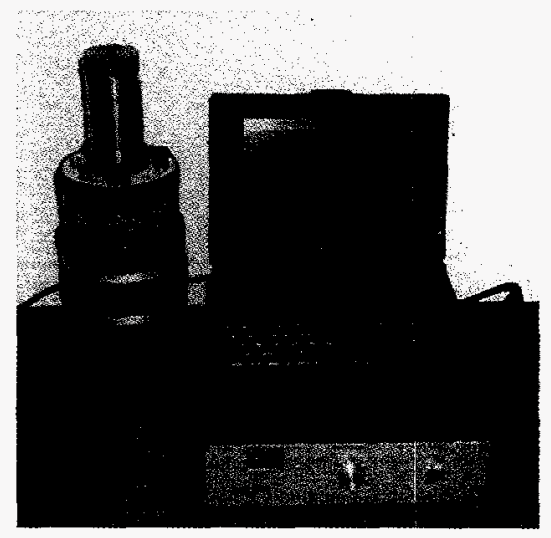
used in Idaho national Engineering and Environmental Laboratory's PINS system. This provides a high-performance system that is also radiologically safe and environmentally clean. The method is highly penetrating, illuminating 1meter depths in common objects. The tool will be useful in explosives detection, humanitarian demining, anti-smuggling of contraband, and oil- and gas-well analyses.

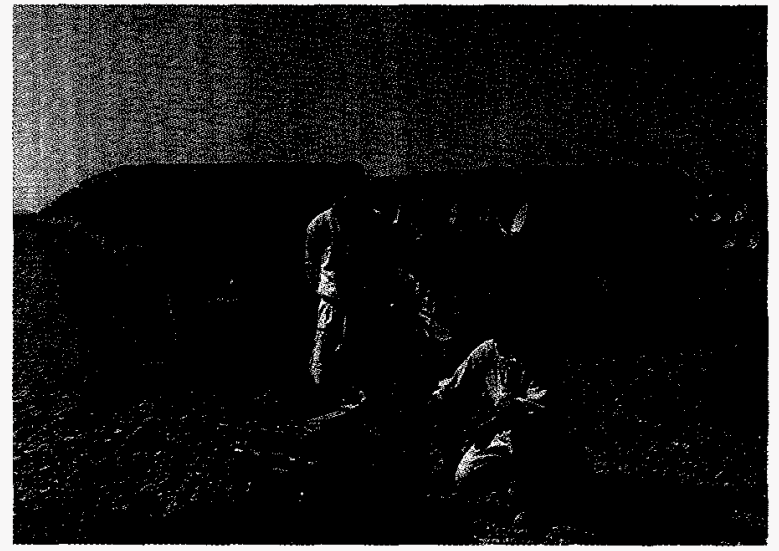

\section{Advantages}

- Rapid, sensitive, invasive chemical-analysis tool; remote analysis possible

- No sample preparation

- Identification of $60-70 \%$ of all chemical elements

- Safe, nonradioactive when powered off

- Applications include chemical-weapons inspection and destruction, toxic waste, nuclear material control, law enforcement 


\section{Beryllium: A Responsible Approach}

\section{IPP Supplies Technical Management for ISTC Initiative Project Sapphire Commitment to Kazakstan}

Beryllium metal has been used in defense, space and nuclear applications which exploit the unique physical and mechanical properties of the material. Commercial applications have been limited to small beryllium additions in copper-beryllium alloys used for tools and electrical components. Commercial applications could be greatly enhanced if the beryllium toxicity

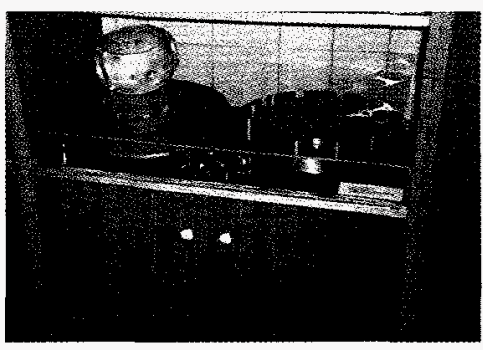
problems were addressed, and consumer products were manufactured using safe, environmentally friendly manufacturing techniques.

IPP is responsible for the technical coordination of a large project being conducted by the Ulba Metallurgical Plant (UMZ), Ust-Kamenogorsk, Kazakstan. This plant is the sole producer of beryllium metal in the former Soviet Union. ISTC is supplying the project funds to Kazakstan under an agreement covered by Project Sapphire. The estimated overall value of this project is $\$ 25$ million, which is a conservative number based on the value of existing beryllium metal resources in Kazakstan.

Resolution of the toxicity issues is critical to the success of this project and all work is being performed under guidance from the United States National Institute of Health. Commercialization depends on the successful partnering between one or more US beryllium manufacturing firms and UMZ. Significant steps were taken this past year with the assistance of IPP funding. A meeting was held with the US beryllium technology community at which the UMZ program was reviewed, and suggestions for improvements were made. Then, a meeting was held with UMZ representatives and a subset of the US beryllium community at Los Alamos.

The outcome of the latter meeting was a protocol that outlined some strong possibilities for collaboration with Brush Wellman Incorporated, Starmet, formerly Nuclear Metals, Incorporated, and with several technical activities at Los Alamos including beryllium sensitivity studies and detection technology development.

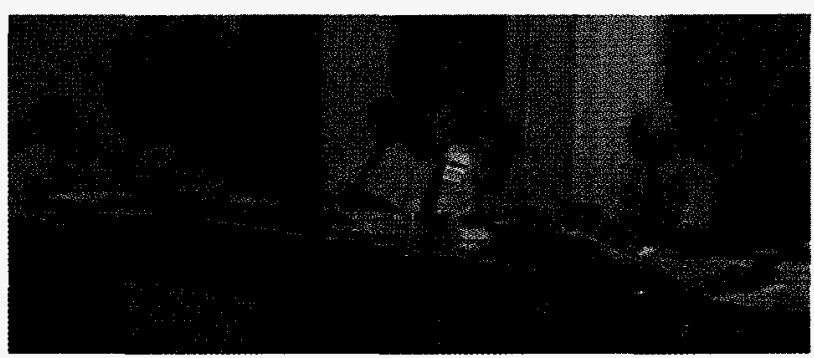




\section{The National Center on Biotechnology of The Republic of Kazakstan and Pacific Northwest National Laboratory (PNNL)}

\section{Production of Carotenoids and Related Products Using Fungal Fermentation}

The Pacific Northwest National Laboratory is collaborating with the National Center on Biotechnology to develop a fermentation process for the production of carotenoids, carotene, and fatty acids. The process is based upon the use of Blackeslea trispora and its ability to produce high yields of $\beta$-carotene and other products from soybean-corn meal-sunflower oil medium. The National Center on

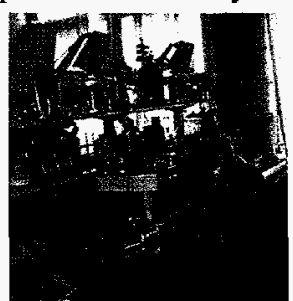
Biotechnology has investigated the use of this fungi as a fermentation source for carotenoid-containing animal feeds and crystalline $B$-carotene for several years.

The initial step of this research is to establish and confirm the medium components necessary to provide accelerated growth rate of the fungi and enhanced carotinoid production. This information can be used to model the cultivation requirements to forecast the maximum utilization of the medium components and the optimized production of the various products. The second step of this research shall involve culture selection to maintain large-scale production of the carotenoids. This step is necessary to remove inhibitors of the accelerated fermentation. Once the best culture is selected, an extraction process (including cell disruption) will be developed for specific products within the fermentation mixture.

\section{State Research Center of Virology and Biotechnology, VECTOR and Pacific Northwest National Laboratory (PNNL)}

Immunoassay for Human Antibodies Against Western Liver Fluke

The Pacific Northwest National Laboratory is collaborating with the State Research Center of Virology and Biotechnology - Vector to demonstrate proofof-principle for diagnostics of liver fluke (Opisthorchis felineus) infection in humans. What is proposed is the development of a blood assay to detect the presence of the fluke in the blood system.

The improvement of this method over the previous ELISA method is based on using recombinant technology to produce specific antigen and antibody to this antigen. This will greatly enhance the specificity/sensitivity of the detection of circulating antibody.

These efforts will result in a test "panel" for pathogenic flukes that will be useful to the diagnostician in determining the course of treatment for patients afflicted with these

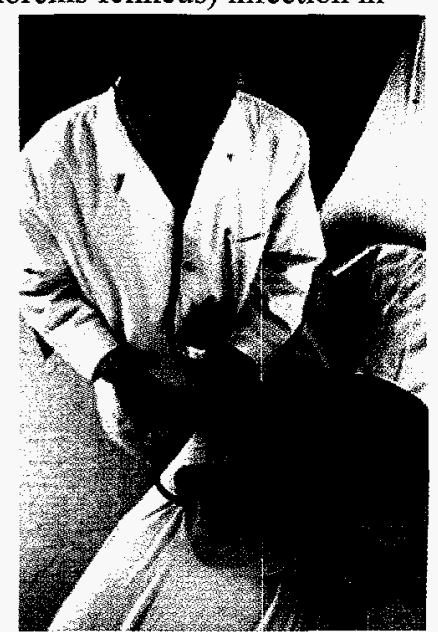
parasitic infections. 


\section{Treating Contaminated Hearth Ash in the Republic of Belarus}

This project is a follow up to a previous IPP project between Brookhaven National Laboratory Environmental \& Waste Technology Center and the Institute of Power Engineering Problems (IPEP) to investigate the feasibility of Thermoplastic Encapsulation for treatment of contaminated hearth ash in the Republic of Belarus. Initial efforts focused on the Sulfur Polymer Encapsulation process. Belarus hearth ash was collected and characterized and shipped to the US for treatability studies.

Dr. Alexandre Grebenkov, Laboratory Head at the Institute of Power Engineering Problems visited BNL to discuss the progress of this project. BNL presented a plastic pallet manufactured from simulated Belarus biomass conversion ash and recycled plastic. This project is investigating additional thermoplastic process(es) (e.g., polyethylene encapsulation) for treatment of ash products generated as a result of burning contaminated biomass in Belarus. Up to 70 weight $\%$ ash, can be incorporated in plastic to produce secondary products and reduce exposure to contaminants. Agreement in principle was reached on the basis for a Thrust II proposal to scale-up and demonstrate thermoplastic ash treatment.

\section{Advantages}

- The proposed demonstration will provide technology transfer needed to help remediate contaminated sites within the Republic of Belarus, thus reducing potential human health and environmental impacts.

- The Belarus Ministry of Fuel and Energy is interested in exploring commercialization of technologies to treat ash residues from contaminated biomass energy conversion plants that are planned. 


\section{Creating a Global Network The IPP Telecommunications Project}

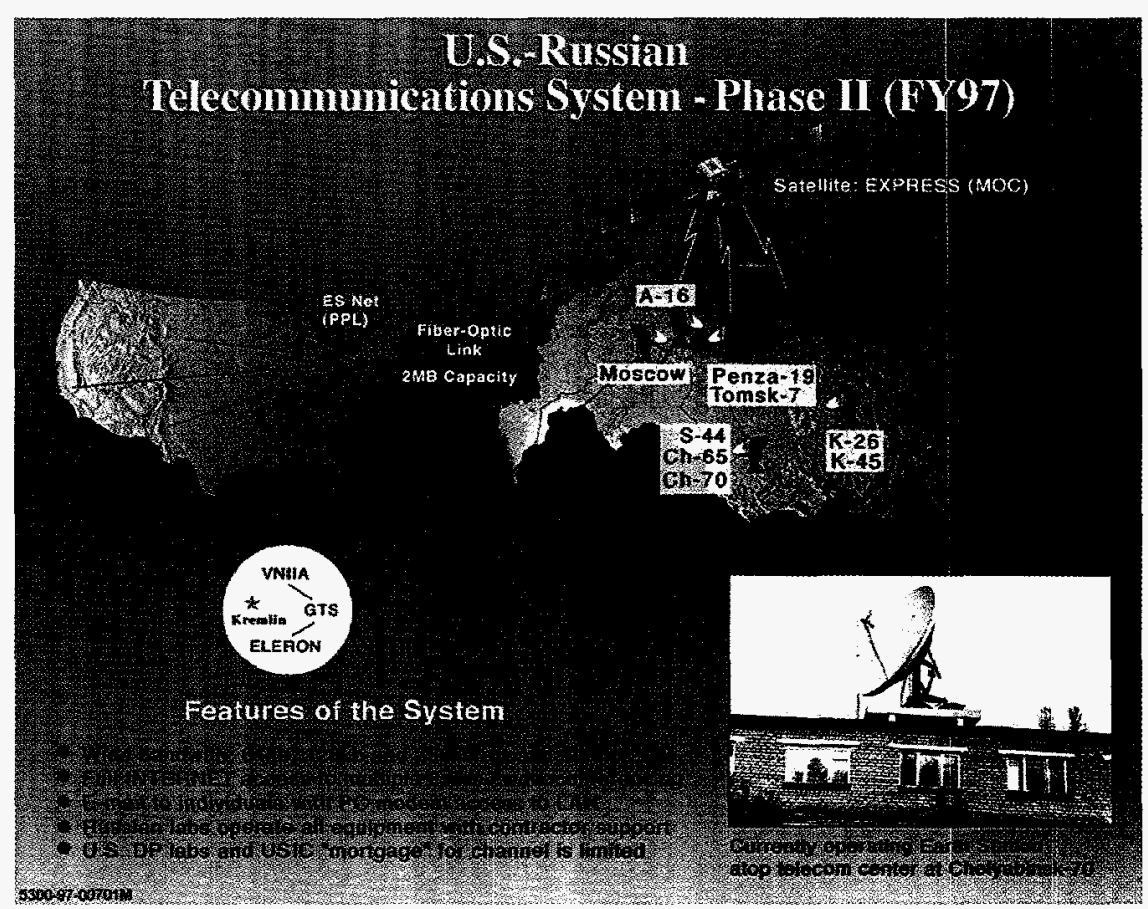

It has been argued that enhanced communications with the formerly closed cities and institutes of the NIS is one of the most important nonproliferation projects within the entire IPP program. The ability to directly interface with our technical counterparts permits detailed discussions and transfer of data without the expense and risk of foreign travel. Perhaps more importantly, however, the fact of direct access to working level personnel is, in itself a powerful nonproliferation incentive and early warning device.

The IPP telecommunications program began in 1994 with contract negotiations at both Chelyabinsk-70 and Arzamas-16. By the end of FY97, both of these facilities had local area networks and high data rate connections to wide area networks via Russian-owned satellite systems. In FY98, a number of additional facilities including the Institute of Automatics, Krasnoyarsk-26, and Eleron will be added to the network. This expansion will continue through FY99 as nuclear, chemical, and biological weapon sites in Russia as well as other NIS locations are added to the net. Following the IPP commercialization model, we have trained personnel from both Arzamas and Chelyabinsk to become "system installers" so that they can develop this line of business as an independent enterprise, in and of itself.

Each of the installations features wide bandwidth, full internet access, videoconferencing capability and email for any individual with PC modem access to the local area netwerk. IPP subsidizes the initial installation and the initial year's satellite access fees. The institute or facility assumes those costs in subsequent years. 


\title{
Managing Nonproliferation Knowledge.........
}

\begin{abstract}
The Nuclear Non-Proliferation Information Group at Los Alamos National Laboratory has created a complex global "Extranet" to improve coordination, communication and program operations between major US nonproliferation programs, other foreign governments, and global industry. Tremendous effort has been focused on improving the effectiveness of operations, avoiding redundancy and duplication of effort amongst the many participants, and making the vast amount of technical information gained in this program available to all interested parties. This system is an "Extranet" as many databases, servers, and the system architecture is shared between multiple programs and organizations, namely DOE's Initiatives for Proliferation Prevention, DOE's Materials, Protection, Control \& Accountability (MPC\&A) Program, and the International Science \& Technology Center (ISTC) in Moscow.
\end{abstract}

Data input responsibilities are shared amongst the different participants. All proposals, projects, deliverables, successes, and financial tracking occur within a complex project tracking database. Members from the 11 DOE Laboratories and DOE Headquarters are connected to servers located throughout the country. Interested parties can access IPP, MPC\&A, and other NIS information and success stories through Los Alamos National Laboratory's Center for International Security Affairs site at http://cisa.lanl.gov.

All database information is updated every twenty minutes. A high level of security is built into this system to allow different levels of access to these databases through the Lotus Notes groupware system or via the web site. IPP databases currently available include:

Projects: Proposals, Projects, Financial tracking and reporting mechanisms Snapshots: One page success stories about each IPP project Technologies Available: NIS Institute and US Laboratory proposal topic suggestions

This information system has offered these nonproliferation programs a powerful collaborative tool that encourages and supports problem-solving, research and development, and more efficient program operations. It has given the US government a method to support its nonproliferation objectives by building an infrastructure which encourages participants from US and foreign governments, from NIS Institutes, and from global industry to work jointly to discover opportunities and solutions associated with nonproliferation threats and economic resurrection. 


\section{Conclusions}

The impact of IPP has been greater than anticipated. IPP is playing an important role in supporting US nonproliferation objectives; however, stabilizing the economic situation in the NIS is dependent on private sector investments well beyond the scope of even the most ambitious government programs.

IPP is designed to identify opportunities for US industry to invest in high technology enterprises resulting in job creation in the NIS as well as in the United States. The success of IPP is due, in part to the response from US industry to participate in the cost-shared partnerships, contributing almost $\$ 2.00$ in funds or services-in-kind for every $\$ 1.00$ of Federal funds.

IPP has had many impacts:

- Reduction of the incentive for persons with knowledge of weapons of mass destruction technology and capabilities to act contrary to their nonproliferation responsibilities by engaging them in carefully reviewed, peaceful commercial projects.

- Providing suitable non-military options to generate commercial income resulting in the long term restructuring in the NIS Weapons of Mass Destruction infrastructure.

- Placement of the ultimate responsibility for a strong nonproliferation regime on the NIS. This is accomplished by developing necessary indigenous incentives, expertise, and capability. IPP is cooperative and reciprocal in nature.

To date, over 360 projects have been initiated - 85 percent with institutes in the Russian Federation - including over 300 "Lab-to-Lab" projects (Thrust I) and over 60 industry cost-shared projects (Thrust II). Several Thrust II projects have evolved to Thrust III efforts that eliminate the need for government funding. Projects have engaged over 4,000 weapons scientists, engineers and technicians.

Using IPP as a template, the numerous demonstrations of technology transfer from military to commercial applications have prompted our NIS colleagues to pursue similar initiatives using NIS funds, and to secure matching funds for IPP projects from the NIS governments.

Perhaps the most significant achievement has been the realization by NIS colleagues that sophisticated science and engineering for non-military activities can be stimulating, challenging, and more rewarding then defense work.

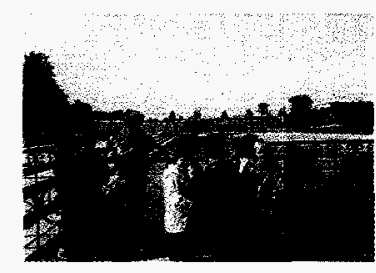

